\title{
PELATIHAN PENGAMBILAN FOTO UDARA MENGGUNAKAN UAV UNTUK MENDUKUNG PARIWISATA DI GUNUNG KIDUL
}

\author{
Catur Budi Waluyo ${ }^{1}$, Denny Dermawan², M. Jalu Purnomo ${ }^{3}$ \\ ${ }^{1,2}$ Program Studi Teknik Elektro \\ ${ }^{3}$ Program Studi Aeronautika \\ Sekolah Tinggi Teknologi Adisutjipto \\ Jl. Janti Blok R Lanud Adisutjipto, Yogyakarta \\ catur_budiwaluyo@yahoo.co.uk
}

Received: April 2020; Accepted : Mei 2020; Published : Juli 2020

\begin{abstract}
The development of unmanned aircraft technology encourage for new infrastructure and development in the tourism sector. Challenges for the development of tourism in Gunungkidul Regency included the development of tourism and cultural villages, access roads to tourism objects, and coastal tourism objects. So, the community service partner was the Gunungkidul Regency Tourism Office. The main objective in this community service activity was to increase knowledge and skills of UAV (Unmanned Aerial Vehicle) to support the development of tourism facilities, particularly in aerial photo taking. The target achieved at this stage was to increase knowledge about UAVs and the ability to control UAV aircraft for taking aerial photographs to support tourism in Gunung Kidul. Increasing ability to control UAVs was done through practice. While increasing knowledge was done through explanation about UAVs. This activity has been able to achieve the expected goals and targets, so that partner can recognize and be able to control the UAV.
\end{abstract}

Keywords: Training, Unmanned Aerial Vehicle, Gunung Kidul.

\begin{abstract}
Abstrak
Perkembangan teknologi pesawat tanpa awak mendorong adanya infrastruktur baru dan pengembangan dalam bidang pariwisata. Tantangan untuk pengembangan pariwisata di kabupaten gunungkidul antara lain pengembangan desa wisata dan desa budaya, pengembangan jalan akses ke obyek wisata, dan pengembangan obyek wisata pesisir pantai. Sejalan dengan hal tersebut maka mitra pengabdian masyarakat ini adalah Dinas Pariwisata Kabupaten Gunung Kidul. Tujuan utama dalam kegiatan pengabdian masyarakat ini adalah meningkatkan pengetahuan dan ketrampilan dalam dunia UAV (Unmanned aerial Vehicle) untuk mendukung pengembangan fasilitas bidang pariwisata, khususnya dalam pengambilan foto udara. Target yang dicapai pada tahap ini adalah meningkatkan pengetahuan tentang UAV dan kemampuan mengendalikan pesawat UAV untuk pengambilan foto udara untuk mendukung pariwisata di gunungkidul. Peningkatan kemampuan mengendalikan UAV dilakukan melalui praktek lapangan. Sedangkan peningkatan pengetahuan dilakukan melalui pemaparan tentang UAV.
\end{abstract}


Kegiatan ini telah mampu mencapai tujuan dan target yang diharapkan sehingga mitra dapat mengenal dan mampu mengendalikan UAV.

Kata Kunci: Pelatihan, Unmanned aerial Vehicle, Gunungkidul.

\section{Latar Belakang Masalah}

Saat ini pariwisata di Indonesia khususnya di gunungkidul menjadi unggulan di pemerintah daerah Bantul. Dikarenakan potensi alam yang dimiliki gunung kidul mempunyai keindahan, dan keunikan tersendiri, ada sekitar 60 objek wisata di kabupaten gunungkidul yang belum dijelajahi oleh masyarakat di sekitarnya. Sejak tahun 2007 Pemerintah daerah gunung kidul meningkatkan akses ke berbagai objek wisata. Hal itu ditunjukan dengan meningkatnya jumlah wisatawan domestic dan mancanegara sejak tahun 2012 hingga sekarang. Perkembangan pariwisata ini diharapkan mampu menggerakkan perekonomian masyarakat di kabupaten gunungkidul dan sekitarnya. Pada penelitian Andreas N. Rahardyanto dkk dalam [1] dengan judul ekonomi pariwisata gunungkidul: arah dan potensinya menunjukan jumlah wisatawan dan daya tarik pengunjung semakin meningkat.

Di zaman yang serba modern ini masyarakat hampir di seluruh dunia memanfaatkan teknologi yang ada, mulai dari menyampaikan informasi sampai dengan foto udara dengan menggunakan Unmanned Aerial Vehicle (UAV). Teknologi tersebut dapat digunakan untuk mengambil gambar objek wisata melalui foto udara di gunungkidul yang indah dan unik tersebut. Sejalan dengan hal tersebut, maka pada pengabdian kali ini melakukan pelatihan pengambilan foto udara dengan menggunakan UAV, yang nantinya hasil foto udara tersebut dapat digunakan untuk fasilitas promosi dan pengembangan objek wisata di gunungkidul.

Target dan luaran yang diharapkan dari kegiatan pengabdian kepada masyarakat ini yaitu bertambahnya kemampuan dan ketrampilan dinas pariwisata dalam menggunakan teknologi drone untuk menunjang pariwisata di gunung kidul. Selain itu dapat meningkatkan kompetensi dinas pariwisata gunung kidul menggunakan drone dalam pemetaan dan pengambilan data primer maupun sekunder di desa wisata gunung kidul.

\section{Masalah}

Mitra dalam hal ini adalah pemerintah gunungkidul melalui dinas pariwisata yang merupakan salah satu instansi yang langsung terkait terhadap pengembangan pariwisata di gunugkidul. Pada mitra ini ketrampilan dalam penguasaan teknologi khususnya pengambilan foto udara sebagai sarana promosi masih rendah, sehingga perlu ada program pengabdian yang dapat menyelesaikan masalah-masalah yang dihadapi. Untuk prioritas permasalahan yang akan diselesaikan antara lain: Pengenalan perangkat UAVdan pemahaman teknik pengambilan foto udara menggunakan UAV.

\section{Metodologi Pelaksanaan}

Berdasarkan permasalahan yang telah diidentifikasi pada bagian Pendahuluan dan solusi yang ditawarkan pada bagian Solusi Permasalahan, maka langkah yang akan dilakukan dalam melaksanakan solusi dari permasalahan mitra adalah

a. Survei Lapangan

Kegiatan survei lapangan bertujuan untuk mencari informasi mengenai solusi untuk kegiatan pengabdian masyarakat yang meliputi wawancara terhadap perwakilan dinas pariwisata tentang pengetahuan dan pemahaman UAV untuk menunjang promosi dan pengembangan objek wisata di dinas pariwisata gunungkidul. Selain itu, pengabdi 
juga melakukan survei lapangan terhadap faktor lapangan yang meliputi lokasi pelatihan pemotretan terhadap lapangan terbang terdekat, halangan atau obstacle serta jalur larangan penggunaan frekuensi. Setelah terjadi kesepahaman, maka selanjutnya dilakukan kegiatan pelatihan.

b. Pelatihan

Kegiatan pelatihan bertujuan untuk memberikan penyuluhan tentang pentingnya UAV dalam menunjang promosi dan pengembangan objek wisata. Pada metode ini memberikan pengenalan tentang pesawat tanpa awak dan pelatihan dalam mengendalikan pesawat UAV. Pelatihan ini memanfaatkan teknologi pesawat tanpa awak agar dapat digunakan untuk mendukung pengembangan pariwisata di gunung kidul. Para peserta pada tahap pertama dikenalkan tentang teknologi pesawat tanpa awak atau Unmanned aerial Vehicle $(U A V)$, jenis-jenis pesawat UAV yang dapat digunakan untuk mendukung pengembangan pariwisata, dan pengenalan komponen-komponen yang butuhkan dalam perakitan UAV.

Pada tahap kedua, untuk meningkatkan ketrampilan dalam mengendalikan UAV para peserta diberikan pengenalan tentang langkah awal dalam persiapan menggunakan UAV dan praktik lapangan mengendalikan UAV. Pengenalan langkah awal dalam penggunaan UAV meliputi cara menghidupkan Remote Control (RC), cara menghubungkan RC dengan pesawat UAV dan cara menggunakan tombol yang ada pada RC. Setelah tahap pengenalan langkah awal selesai kemudian para peserta di latih menerbangkan pesawat UAV serta uji coba sendiri dalam menerbangkan dan mengendalikan pesawat UAV. Dalam hal ini misalnya pelatihan pengendalian UAV, sehingga nantinya mitra dapat dilepas dan mengendalikan UAV secara mandiri.

c. Pendampingan

Pendampingan bertujuan untuk memastikan bahwa mitra mampu menerapkan hasil pelatihan yang telah diberikan secara mandiri. Selain itu, pada pendampingan ini, mitra diberikan produk berupa video profil yang merupakan hasil pemotretan foto udara di salah satu pantai pada kasus ini yaitu pantai indrayanti.

\section{Hasil dan Pembahasan}

Kegiatan pengabdian kepada maasyarakat dengan mitra dinas pariwisata gunungkidul yang beralamat Jl. Brigjen Katamso No.1, Wonosari-DIY ini dimulai dengan kegiatan survei lapangan yang dilakukan oleh tim pengabdian. Kemudian, setelah terjalin kesepakatan kerja sama dengan mitra maka kegiatan pengabdian kepada masyarakat ini, dengan sepengetahuan kepala dinas pariwisata, dilanjutkan ke tahap pelaksanaan. Hasil kegiatan pengabdian kepada masyarakat yang berbentuk pelatihan dan pendampingan pengendalian pesawat UAV untuk kegiatan foto udara di dinas pariwisata gunung kidul yang dilaksanakan pada tanggal 10 September 2019. Jumlah peserta yang mengikuti pelatihan ini yaitu 15 Orang dan tingkat keaktifan dan minat para peserta pelatihan cukup memuaskan bahkan mereka mengharapkan adanya pelatihan lanjutan setelah kegiatan ini. Pada pengabdian ini ada beberapa kegiatan yaitu:

a. Survei lapangan

Pada kegiatan ini perwakilan dari tim pengabdian melakukan survei dan wawancara terhadap perwakilan dinas pariwisata tentang pengetahuan dan pemahaman UAV untuk menunjang promosi dan pengembangan objek wisata di dinas pariwisata gunungkidul. Selain itu, pengabdi juga melakukan survei lapangan terhadap faktor 
lapangan yang meliputi lokasi pelatihan pemotretan terhadap lapangan terbang terdekat, halangan atau obstacle serta jalur larangan penggunaan frekuensi. Survei lapangan dilaksanakan pada tanggal 5 september 2019. Untuk foto kegiatan survei lapangan di dinas pariwisata gunungkidul dapat dilihat pada gambar 1 .

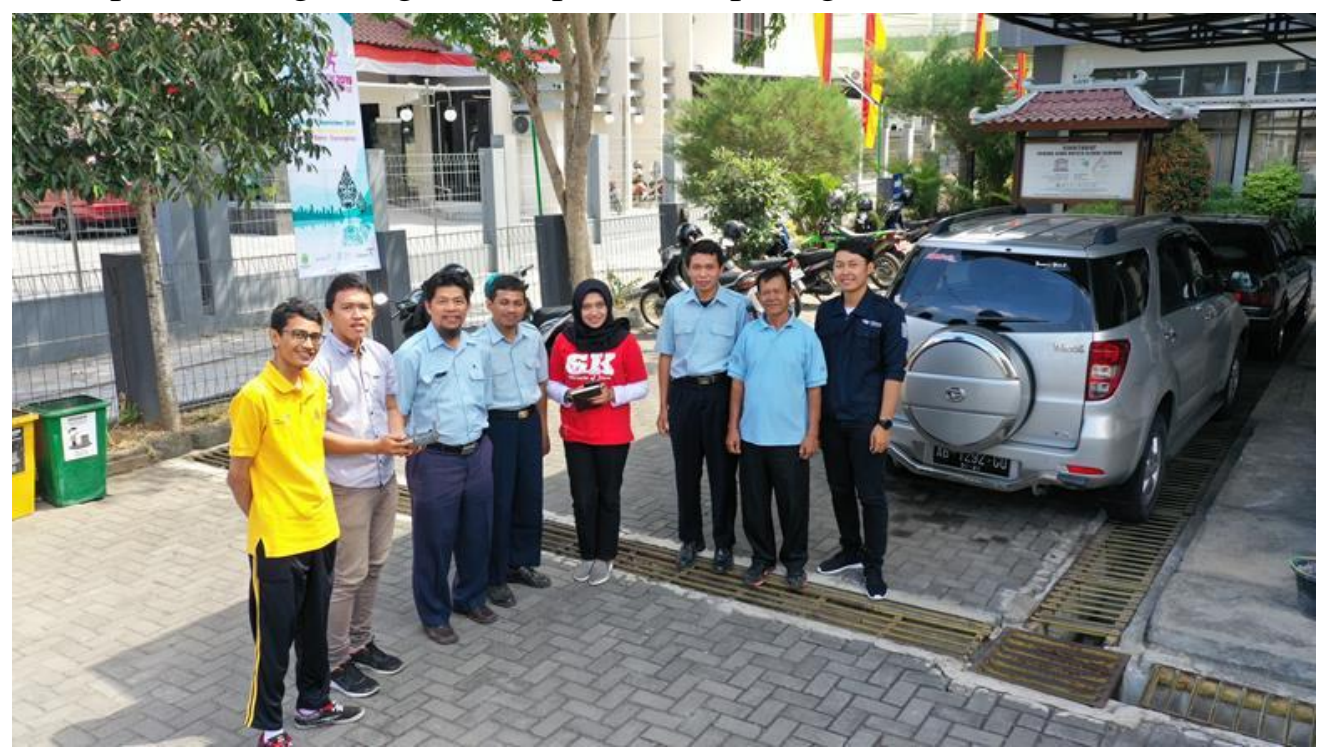

Gambar 1. Kegiatan survei lapangan sebelum pelaksanaan pelatihan

b. Pelatihan Pengenalan UAV dan komponen yang digunakan

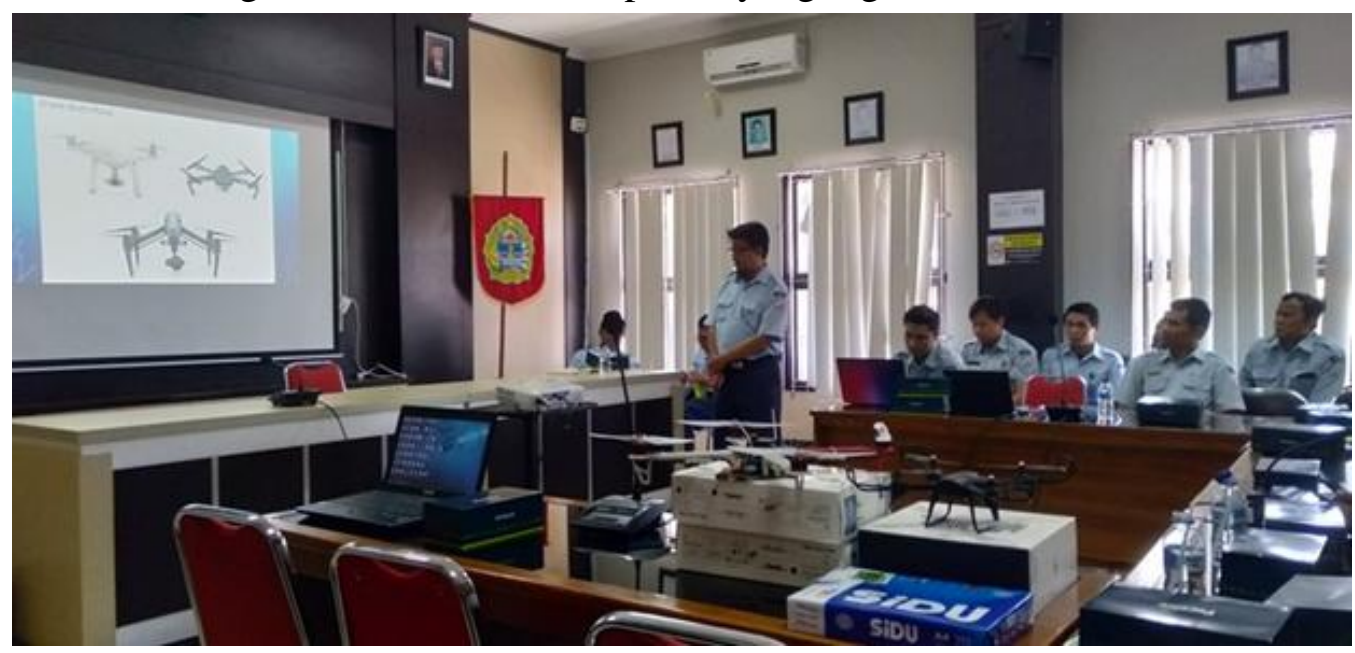

Pengenalan tentang pesawat UAV disampaikan oleh Denny Dermawan, S.T., M. Eng selama 60 menit. Pada sesi pertama dilakukan dengan pengenalan jenis-jenis drone dan fungsinya. Pada sesi ini juga dikenalkan tentang tipe drone dan aplikasi penggunaanya. 


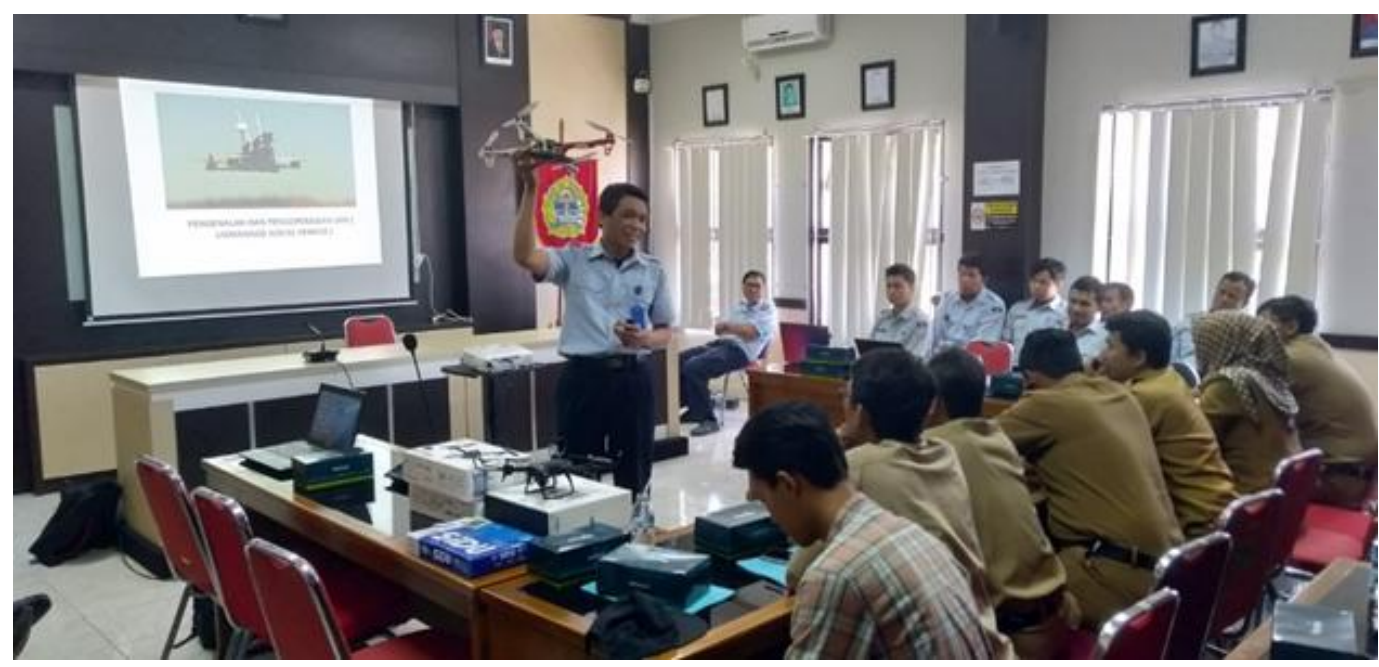

Gambar 2. Peserta dari dinas pariwisata yang antusias mendengarkan tentang komponenkomponen yang digunakan dalam pembuatan pesawat UAV.

Pengenalan tentang komponen dalam pesawat UAV pada sesi kedua disampaikan oleh Catur Budi Waluyo,S.T.,M.T selama 60 menit. Para peserta dari dinas pariwisata antusias mendengarkan tentang komponen-komponen yang digunakan dalam pembuatan pesawat UAV. Pada sesi ini juga di jelaskan tentang langkah-langkah dalam pembuatan drone, estimasi biaya yang diperlukan dalam perakitan drone dan teknik dalam pengambilan foto udara dengan menggunakan drone.

Pengenalan komponen yang diperlukan pada pembuatan drone meliputi frame, Motor Brushless, Electronic Speed Controller (ESC), Flight Control, Baterai, dan Remote Control. Pada pengenalan ini, pemaparan menggunakan presentasi power poin dan disertai dengan gambar-gambar ilustrasi. Pada pengenalan ini juga dijelaskan pengkabelan dalam perakitan drone ini. Untuk pengkabelan dapat dilihat pada gambar 3.

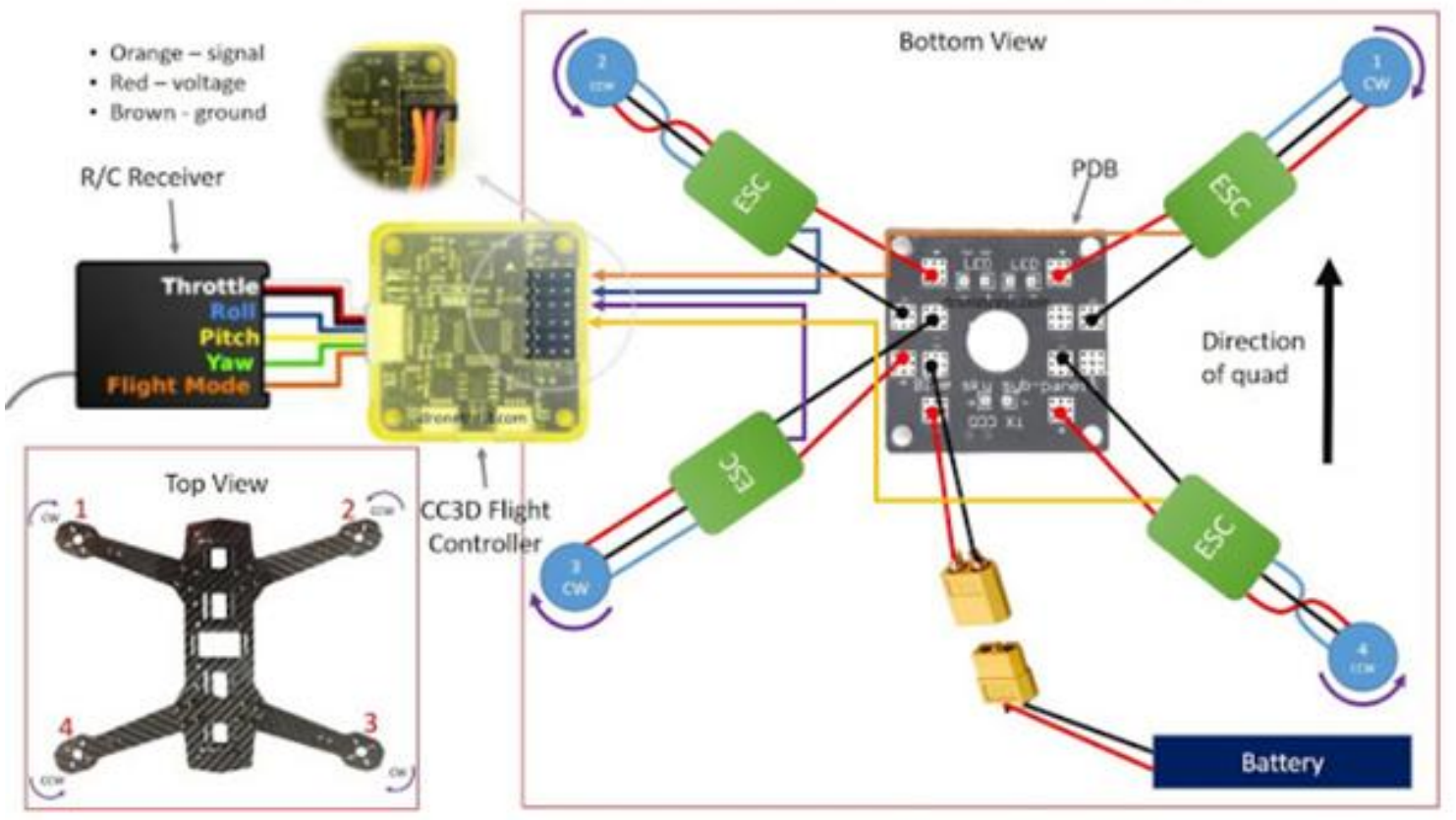

Gambar 3. Pengkabelan pada pesawat UAV ZMR250. 
Pada pengenalan teknik pemetaan spasial ini diarahkan untuk mengatasi kebutuhan dinas pariwisata dalam menunjang perencanaan pembangunan desa wisata. Hal ini dikarenakan masih lemahnya informasi spasial desa wisata baik berupa data primer ataupun data sekunder yang disediakan oleh dinas pariwisata gunung kidul. Materi pengenalan teknik pemetaan yaitu pengertian fotogrametri, aspek-aspek fotografi, Klasifikasi foto udara, Sistem koordinat foto udara, dan Perencanaan misi pemotretan udara.

Materi pengenalan klasifikasi foto udara berupa spectrum elektromagnetik yang dapat digunakan karena tidak semua spectrum dapat digunakan dalam foto udara, selain itu, mengenal jenis kamera, sistem wahana, sudut liputan dan bentuk data yang di gunakan. Sedangkan materi pada sistem koordinat foto udara meliputi sistem koordinat baik koordinat kartesius maupun koordinat kutub. Selain itu, titik pusat foto udara baik itu titik dasar, titik nadir, maupun isosenter juga di jelaskan pada sesi ini. Untuk mengetahui suatu perubahan kedudukan suatu gambar pada suatu foto yang mengubah ciri-ciri perspektif gambar maka pada pengenalan itu dijelaskan tentang distorsi dan pergeseran letak. Materi tentang ilustrasi perpindahan letak gambar karena pengaruh relief ditampilkan pada Gambar 4.

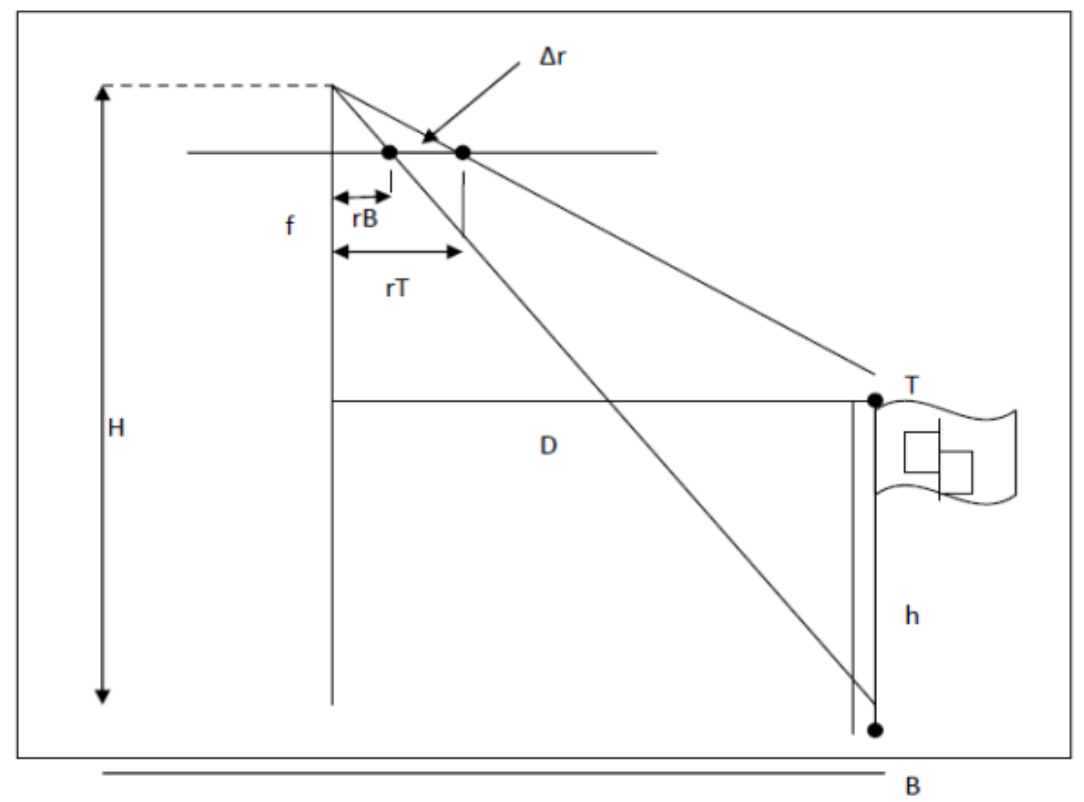

Gambar 4. Ilustrasi perpindahan letak gambar karena pengaruh relief [4]

Keterangan Gambar: $\mathrm{H}$ adalah tinggi terbang; h tinggi objek; B bidang datum; D jarak; T puncak objek; f: fokus; dan rB, rT adalah jari-jari lingkaran dari jarak foto.

Pada materi perencanaan misi pemotretan udara, dijelaskan tentang perhitungan skala foto yang digunakan, dan faktor lapangan yang meliputi lokasi pemotretan terhadap lapangan terbang terdekat, kondisi topografi, kondisi cuaca, halangan atau obstacle, jalur penerbangan serta jalur larangan penggunaan frekuensi.

c. Pelatihan dalam pengendalian drone 
Pada tahap ini langkah awal dalam penggunaan UAV meliputi cara menghidupkan Remote Control (RC), cara menghubungkan RC dengan pesawat UAV dan cara menggunakan tombol yang ada pada RC. Setelah tahap pengenalan langkah awal selesai kemudian para peserta di latih menerbangkan pesawat UAV serta uji coba sendiri dalam menerbangkan dan mengendalikan pesawat UAV.

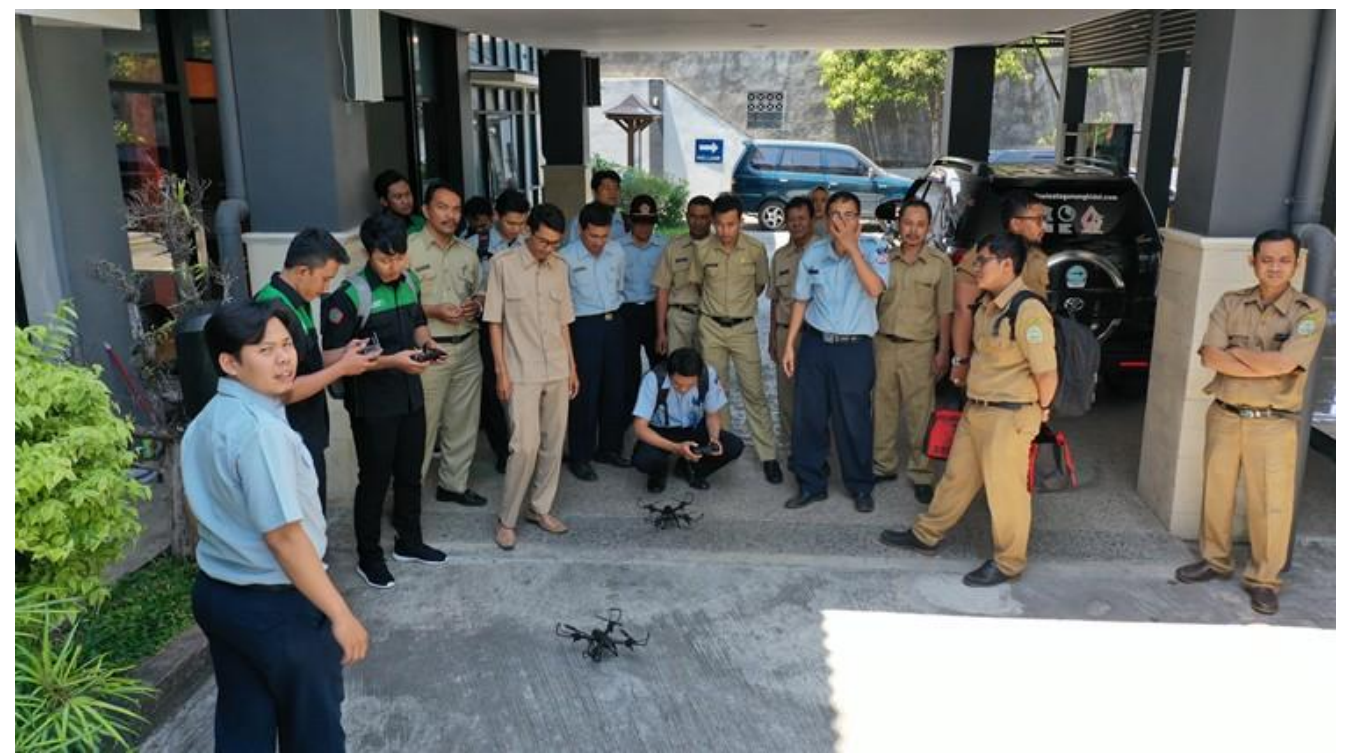

Gambar 5 Persiapan Pelatihan pengendalian UAV

d. Penyerahan cindera mata berupa pesawat UAV kepada dinas Pariwisata

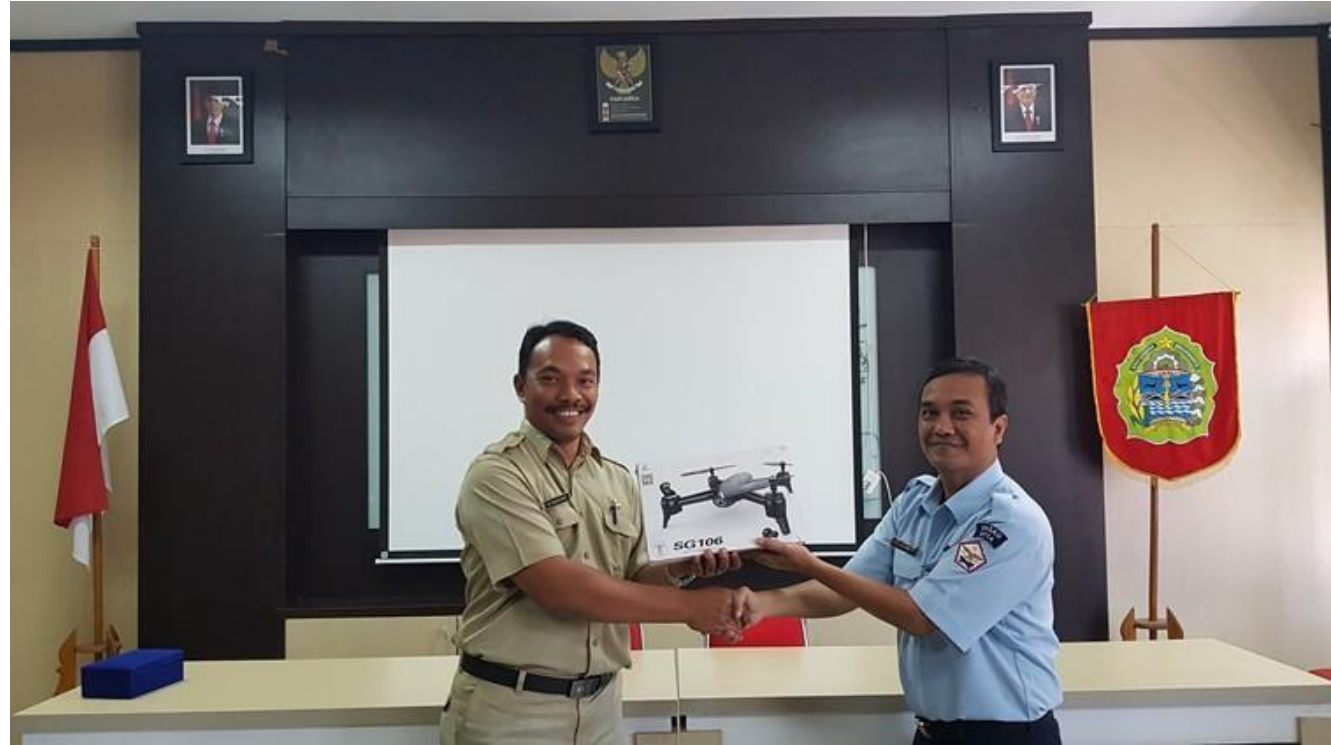

Gambar 6 Penyerahan cindera mata berupa pesawat UAV

Pada kegiatan ini penyerahan cindera mata dari pihak Sekolah Tinggi Teknologi Adisutjipto di wakili oleh Dedet Hermawan S.,S.T., M.T. selaku Wakil Ketua 1 bidang akademik dan pihak dinas pariwisata gunungkidul diwakili oleh Eli Martono, SIP, MPP, MEng selaku kepala dinas pariwisata gunungkidul. Setelah kegiatan penyerahan kenang- 
kenangan selesai kemudian dilakukan foto bersama dengan menggunakan UAV seperti pada gambar 7 .

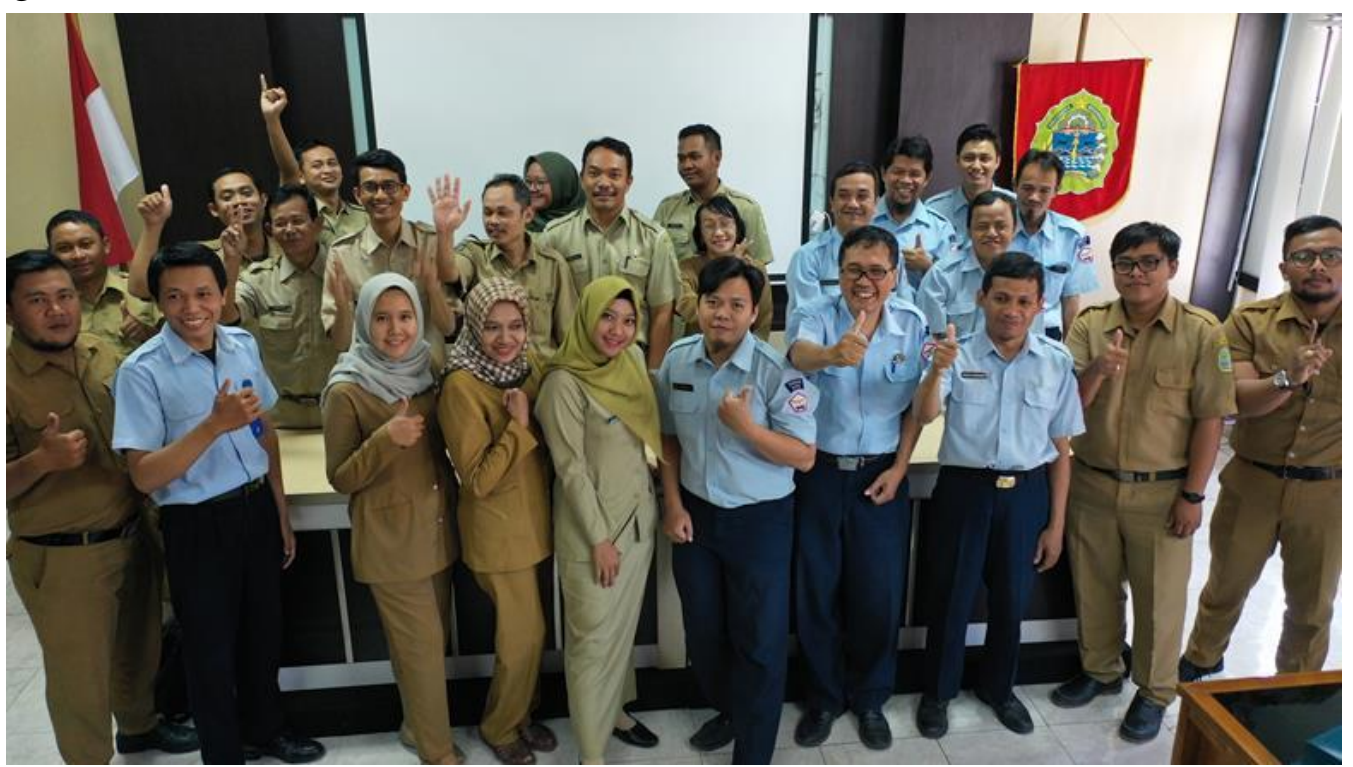

Gambar 7. Pengambilan foto bersama dengan menggunakan UAV

e. Pedampingan

Pada pendampingan ini tidak hanya dilakukan oleh tim pengabdian, melainkan dibantu oleh pihak lain seperti teknisi dari editing foto dan video serta mahasiswa. Target dari pendampingan ini yaitu mitra dapat langsung konsultasi langsung dengan para teknisi dan tim pengabdi memberikan hasil produk berupa video profil yang merupakan hasil dari pemotretan foto udara menggunakan UAV di pantai indrayanti. Pelaksanan pengambilan gambar pada pantai pulang sawal/indrayanti pada tanggal 19 september 2019. Untuk kegiatan pengambilan foto udara di pantai indrayanti dapat dilihat pada gambar 8 .

\section{f. Evaluasi}

Setelah melakukan kegiatan tersebut ada beberapa kendala yang dihadapi dan solusi dalam pelaksanaan pengabdian ini dapat dilihat pada tabel 1 .

Tabel 1. Masalah dan solusi

\begin{tabular}{l|l|l}
\hline No & \multicolumn{1}{|c|}{ Permasalahan } & \multicolumn{1}{c}{ Solusi } \\
\hline \hline 1. & $\begin{array}{l}\text { Peserta belum terbiasa menggunakan } \\
\text { pesawat UAV }\end{array}$ & $\begin{array}{l}\text { Dilakukan pelatihan dalam } \\
\text { pengoperasian Remote Control } \\
\text { dan pesawat UAV. } \\
\text { Diberikan 1 Unit pesawat UAV. }\end{array}$ \\
2 & $\begin{array}{l}\text { Diperlukan pesawat UAV untuk } \\
\text { latihan } \\
\text { Dibutuhkan video profil hasil dari } \\
\text { pengabdian }\end{array}$ & $\begin{array}{l}\text { Di buatkan video profil pada salah } \\
\text { satu objek wisata pada kasus ini } \\
\text { mengambil objek wisata di pantai } \\
\text { pulang sawal atau indrayanti. }\end{array}$ \\
\hline
\end{tabular}




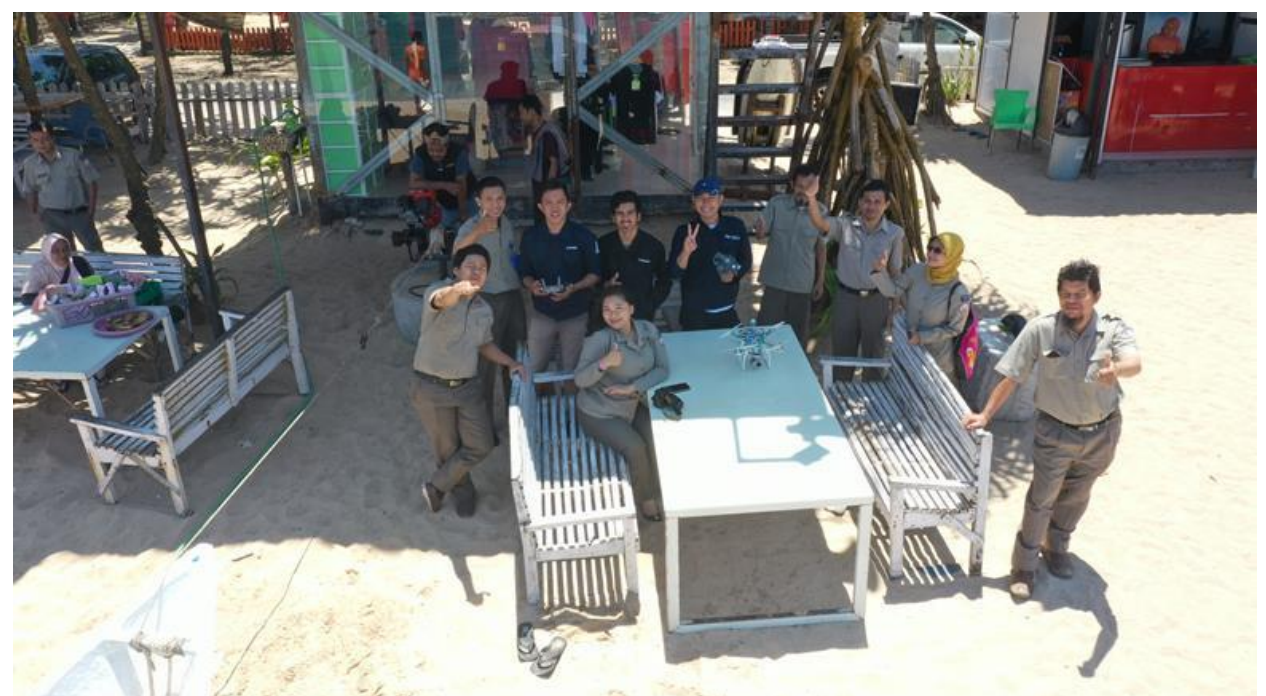

Gambar 8. Pengambilan foto udara pada pantai pulang sawal/indrayanti.

\section{Kesimpulan}

Berdasar pada hasil kegiatan yang telah dipaparkan maka kegiatan pengabdian pada masyarakat ini telah terlaksana dengan baik dan sesuai dengan tujuan yang diharapkan. Selain itu, dengan kemajuan teknologi UAV dapat digunakan untuk pengambilan foto udara dalam menunjang promosi dan pengembangan desa wisata gunungkidul. Dengan diadakan kegiatan pengabdian ini, maka dinas pariwisata dapat membuat terobosan baru dalam meningkatkan kualitas layanan dan informasi di objek wisata.

\section{Ucapan Terima Kasih}

Penulis ingin mengucapkan terima kasih dan penghargaan yang setinggi-tingginya kepada Sekolah Tinggi Teknologi Adisutjipto atas bantuan dana pengabdian multidisiplin yang diberikan sehingga pengabdian ini dapat terlaksana dengan baik.

\section{Daftar Pustaka}

[1] Beritasatu, 2017, Pariwisata Gunung Kidul Hasilkan PAD Rp 515 Juta, https://id.beritasatu.com/home/pariwisata-gunung-kidul-hasilkan-pad-rp-515-juta/162008, di akses 21 Maret 2019.

[2] Sjaf S. dkk, 2016, Modul Pelatihan Pemetaan Berbasis Drone Desa, IPB, Jawa Barat

[3] Waluyo, C. B. (2018). Pelatihan Pembuatan Running Text Berbasis Matrix Display LED Dengan Menggunakan HD-U6A. KACANEGARA Jurnal Pengabdian Pada Masyarakat, 1(1), 7. doi:10.28989/kacanegara.v1i1.259

[4] Shofiyanti, R. (2011). Teknologi pesawat tanpa awak untuk pemetaan dan pemantauan tanaman dan lahan pertanian. Informatika Pertanian, 20(2), 58-64. 
[5] Calesmart, 2019, Bingung cara merakit drone?Begini cara merakit sendiri quadcopter jenis ZMR250, https://calesmart.com/artikel/Bingung-cara-merakit-droneBegini-cara-merakitsendiri-quadcopter-jenis-ZMR250_150.html, di akses 21 Maret 2019

[6] Calesmart, Pengenalan Pesawat Unmanned Aerial Vehicle untuk Auto Pull Up, https://www.blog.calesmart.com/2017/02/08/547/, di akses 21 Maret 2019

[7] Publisher, 2018, 58 Tempat wisata di gunungkidul yang wajib dikunjungi, https://eksotisjogja.com/tempat-wisata-di-gunungkidul/, di lihat 20 Maret 2019

[8] Academia, Potensi Pariwisata Gunung Kidul - Penelitian Majalah Pertama, https://www.academia.edu/20094349/Potensi_Pariwisata_Gunung_Kidul_-

_Penelitian_Majalah_Pertama dilihat 20 maret 2019

[9] Dinas Pariwisata, 2019, Website resmi dinas Pariwisata Gunung Kidul, http://wisata.gunungkidulkab.go.id/we, dilihat 20 Maret 2019

[10] Anonim, 2016, Rencana Induk dan detail kawasan strategis pariwisata nasional (KSPN) Karst Gunungkidul dan sekitarnya, https://visitingjogja.com/download/statistik-pariwisata/ dilihat 20 Maret 2019

[11] Tokopedia, 2019, Dji Phantom 3 Standard Bergaransi Resmi 1 tahun, https://www.tokopedia.com/djipro/dji-phantom-3-standard-bergaransi-resmi-1-tahun dilihat 21 Maret 2019 